\title{
Winter Pasture Lands of Azerbaijan and their Agroecological Features
}

\author{
ZH Aliyev* \\ Institute of Soil Science and Agrochemistry of ANAS, Azerbaijan
}

*Corresponding author: ZH Aliyev, Institute of Soil Science and Agrochemistry of ANAS, Azerbaijan.

Received Date: April 13, 2019

Published Date: May 02, 2019

\begin{abstract}
Summary
In recent years, the degradation and depletion of the winter pastures have led to the emergence of resuscitation of the base of animal feed. In connection with this, we have an in-depth assessment of the agro-ecological basis and the relevance of the actual task. In the article presents the analysis of the current state of the problem and the agro-productive grouping. In the result, researches on agrochemical, agro-technical and agroproductive activities are carried out.

\section{Annotation}

Natural and anthropogenic impacts of natural soil, grass cover and mainly pasture (degradation), degradation of desertification and degradation of forest ecosystems have led to a considerable sharp reduction in the feed base for animal husbandry development. For a well-known purpose in the country of strategic importance, the assessment of existing natural and cultural pasture areas in the country from their agroeconomic security perspective, using scientifically-based research in the field of compilation and improvement of effective methods is a problem of agrarian science's urgency. Here, analyzes the modern agroecological situation of the pastures, evaluates land and agrochemical grouping and so on. it is emphasized that it is important to carry out comprehensive measures to improve the quality of the area in the affected areas.
\end{abstract}

Keywords: Pasture lands; Pastures; Pastures; Surface improvement measures; Climatic elements; Agroecological assessment

\section{Introduction}

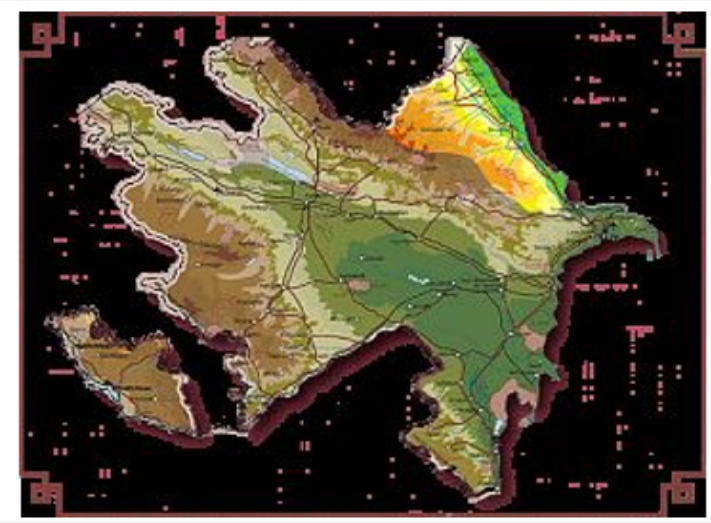

Figure

(Figure) The fact that agriculture has been degraded by important degraded lands in the Republic of Azerbaijan, including the natural pasture and mowing areas, is a consequence of their lack of productivity due to the use of animal breeding for their development purposes. On the other hand, the structure of the oath is low in the high nutritional concentrates causing excessive loading of natural forage areas, erosion and salinization of land as a result of their uncontrolled exploitation, serious damage to the country's forest resources, water resources and the environment as a whole.

In order to increase productivity through the development of livestock production in more progressive ways in the country, to strengthen the protection of summer pastures and mowers, to increase their use and to ensure biodiversity conservation.

Efficient utilization of land resources, improving fertility, restoration, protection and productivity management are essential for the development of agrarian sector in Azerbaijan and should be carried out on a day-to-day agroecological basis. In addition to the development of agriculture in the country, the development of livestock and grazing agriculture, which is one of the main 
directions of agriculture, requires the expansion of the pastureland and pasture areas and increase the production of feed for internal resources. From this point of view, the object of research confirms that the severe degradation processes observed in winter grazing areas in the selected Gobustan region cause the occurrence of less productive landslides in the danger of extinction from sowing.

Reasoning Research The main reason for the unacceptable change in the natural resource potential is pasture plowing, largescale agromeliorative work, excessive livestock grazing and strong man-caused effects. Thus, the problem of increasing the number of live stock is the irreversible stages of overgrazing as pasture degradation.

Herbaceous degradation leads to a reduction in biodiversity, fragmentation of the biosphere structure and the inability of the ecosystem to control and regenerate itself. The creation of a solid feed base, which is the basis for the improvement of our pasture ecosystems, which is the main habitats for the flora and fauna of the region, as well as the basis of the capacities of the country's economy, is a part of the well-known State Program. Along with these, the research merit is a problem of relevance to the needs of the day in the current market economy and expects its own scientifically-researched research with researches.

\section{Object of Research}

The main purpose of the research was to expand the pastures and grazing areas through the application of the results, using the latest research methods in the complex approach of agroecological features of the country's winter pastures in Gobustan region.

\section{Object and Methodology}

The object of research was winter pastures located in the territory of Qobus, their main soil and vegetation. The soil erosion surveys carried out with the practice of suburban soils, monitoring of dangerous gray-brown soils of widespread erosion in the site of the research object were analyzed and the agroecological assessment was carried out on the basis of commonly accepted methodology of academician GS Mammadov [].

The object of research is the erosion of the territorial lands on the districts

\section{M mystery}

No

Regions General area (thousand ha) Including erosion rate

Unsuccessful areas Erosion-free areas are from it

Ha\% ha\% Weak Medium Violence

12345678910111213

1. Gobustan 153.143 .523 .5143 .776 .524 .413 .033 .517 .985 .8 45.9

2. Shamakhi $161,262,839,894,8$ 60,2 38,3 23,3 21,6 13,7 34,9 22,2
3. Ismailli 194.489 .841 .3127 .558 .755 .825 .728 .313 .043 .4 20.0

4. Agsu 108.4 82.8 77.9 39.1 32.1 13.8 11.3 8.5 7.0 16.813.8

Analyzes have been made of [1-3] methodologies taken from soil and plant samples taken from the field of soil research and field studies studies for laboratory studies in selected field of practice.

The main criterion for assessment of grazing lands was the objective indicators affecting their genetic and agrochemical quality: total humus, nitrogen, phosphorus, potassium, total absorbed bases: $0-20 \mathrm{~cm}$; 0 to $50 \mathrm{~cm}$; Reserve $0-100 \mathrm{~cm}$. Reserves of the selected agrochemical indicators $(\mathrm{t} / \mathrm{ha}$ ) were calculated on the generally accepted formula for soil layers. During the research, the same plot of land, plant, landscape, geobotany maps and archive map fund of ANAS Institute of Soil Science and Agrochemistry were used.

\section{Analysis of the Materials of the Study}

Aran Shirvan cadastral region Total area of lands is 6010 thousand hectares. It covers the aran and foothills of the district. The main types of landscapes are semi-desert and medium-sized dry steppes. Depending on the degree of moisture (Md-0.10-0.15), the terrain belongs to the zonal zone.

The average annual precipitation is $250-45 \mathrm{~mm}$. The district is completely heated. The total of temperatures above 100 is 4700 38000 . The winter is soft here. The length of the vegetation period is 226-211 days.

Mainly gray-brown (brown), light gray-brown (chestnut), common gray-brown (chestnut), gray-gray, grass gray, light gray, primrose, grass-grass, forest grass, wet grass soils have spread. Grass-brown, grass-gray and gray soil types are widely used in agriculture. However, in the pastures, there are widespread varieties of these saline and saline, clay, and heavy-grained varieties.

In general, winter pastures in the Shirvan plain cover 119.3 thousand ha of land, which is distributed in the administrative districts as follows: Yevlakh (left bank) - 7,700 hectares; Agdash 9,5 thousand ha; Goychay - 6.6 thousand ha; Ujar - 19,5 thousand ha; Zardab - 19.5 thousand ha; Kurdemir - 51,0 thousand ha. The distributed lands in these districts were evaluated with the following points [4]: dark-brown-brown-100 points; graybrown-85; light gray-brown-73; dark gray-meadow-90; graymeadow-71; gray grass-60; grass-boz-88; grass-gray-brown -75; Subasar meadow-67; gray-63; open-gray-54; elementary-boz-54; meadow-forest-86; wet grass-58; gray-brown - 57 points. These scores belong to the type and type of land on the main bonitet scale. However, the degradation of these varieties in these pastures is specifically associated with the degradation, salinization, granulometric composition, soil thickness, and so on. Indicators should be considered through correction factors. Thus, after taking into account the correlation coefficients, an open bin scale will be established, and the soil can be divided into quality groups. Academician GS Mammadov divided the following qualitative groups on Aravan-Shirvan cadastral region: 
Agroistehsalat grouping of Shirvan plain lands

(According to Academician GS Mammadjeva)

Soil Quality Group Soils included in the Quality Group

Type and semester (honey) Types and varieties of varieties (correction factors)

I group - high-quality soils (100-81 points); dark brown (100); dark gray (90) clay (0.8); heavy-cylindrical (0.90); medium-sized (1.0); light cylindrical (1.0)

II group - good quality land (80-61 points); grass (70); wet grass- (71-68); subassard grass (63-67); clay (0.80); heavycylindrical (0.90); medium-sized (1.0); light gray (0.89) weakly salted (0.91), weakly dehydrated (0.91)

III group - average quality land (60-41 points); grass (70-90); subassard grass (63-67); clay (0.80); heavy-cylindrical (0.90); medium-sized (1.0); light gray $(0,89)$; medium salinity $(0,70)$; weakly insecure (0.91)

IV group - low-quality land (40-21 points); grass (70-90); subassard grass (63-67); clay (0.80); heavy-cylindrical (0.90); medium-sized (1.0); slightly clay (0.89); severe saline (0.50); poorly dehydrated (0.91)

As can be seen from the table, in the Shirvan plain, in the main pasture areas, salty, saline, clay, heavy-gillic, diversity has spread. However, by applying complex agro-measures, as JC Hasanov [5] has shown in his work, it is possible to increase the productivity of pastures at present. The author points out that different plants (phytomeliorants, clover, khash, shabdar, etc.) have a positive impact on soil fertility, soil nutrients, physical-chemical and agrophysical properties. Research by J Hasanov confirms that the influence of organic and mineral fertilizers on the soil fertility, water-physical properties and their regimes at different norms and proportions under the algae plant depends, first of all, on soilclimatic conditions. That is why the above-mentioned issues are relevant and the study of the agrophysical properties and regimes of the Shirvan plain lands is of great theoretical and practical significance.

According to ZR Momsumov's recommendations, mineral fertilizers should be provided locally, not in all areas, but in order to increase the economic efficiency of fertilizers and to reduce the negative impact of their application on the environment. At the same time, the absorption coefficient of nutrients rises, the product grows, along with its quality, improves its water-physical properties and improves its fertility.

Taking into account the above-mentioned recommendations, it is possible to improve the glaciers of the Shirvan peasant pasture in a superficial manner [6].

\section{Results}

- $\quad$ Shirvan peasant winter pasture lands have been heavily damaged due to excessive overload, systematic grazing, neglect, pasture productivity, and biodiversity.

- More than $40 \%$ of winter pasture lands are salty and salty. mainly clay and heavy clay, and their water-physical properties have deteriorated.

- Taking into account the above, surface and root improvement works should be carried out in Shirvan peasant pasture lands, as well as agrotechnical, agrochemical and agro-mechanical complex measures. Thus, the basis of animal husbandry development, it is possible to provide it with cheap and high-quality pasture feed.

\section{Acknowledgement}

None.

\section{Conflict of Interest}

No conflict of interest.

\section{References}

1. ZH Aliyev (2004) Agrophysical properties of reclaimed Azerbaijanis and their productivity. Abstract Diss, 32p.

2. Aliyev, BH Methodical Indication of Soil Erosion in Azerbaijan and its struggle by the publishing house Nurlan-Zia - Baku. 205: 138p.

3. Arunishkina EB (1970) Chemical Chemistry Analysis. Search $2^{\text {th }}$ уч. Пособие для студентов ВУЗов. M, Moscow, Untu, 487 pp.

4. Kosinsky, VV Меркурьев, АГ Chupryakova (2015) Formation of agglomerations of municipal formations: theoretical and practical aspects / PD- Tomsk: Izd vous Tom flour.

5. (1987) Methodological indications on the semiotic cultivation of cereals M, 197p.

6. MOVSUMOV ZR, Gasanova AF (1995) Microorganisms - the productivity of the stockbreeding stock. VOF t V Baku, pp. 125-127. 